\title{
Resection of a Perirectal Leiomyosarcoma via a Posterior Transcoccygeal Approach
}

\author{
Elliot A. Asare, MD, MS, Timothy J. Vreeland, MD, and Barry W. Feig, MD \\ Department of Surgical Oncology, MD Anderson Cancer Center, Houston, TX
}

\begin{abstract}
Introduction. The management of perirectal tumors often requires rectal wall resection, and sometimes a complete proctectomy is required. Access to posterior perirectal masses via a posterior, transcoccygeal approach (Kraske procedure) avoids dissection of the intraperitoneal rectum. Patient. The patient was a 63-year-old male who presented to his primary care physician with debilitating perirectal pain of several months' duration. He did not respond to therapy with pain medications and topical agents, and underwent a lateral internal sphincterotomy for what was thought to be an anal fissure, without relief prior to referral. Diagnostic workup showed a low signal intensity mass on magnetic resonance imaging (MRI), and biopsy revealed high-grade leiomyosarcoma with myxoid features. Staging workup included a contrast-enhanced computed tomography chest, abdomen and pelvis, flexible sigmoidoscopy and endoscopic ultrasound. A lytic lesion in his left ilium on MRI was found to be avid on fluorodeoxyglucose-positron emission tomography scan and
\end{abstract}

was therefore consistent with oligometastatic disease. He received six cycles of adriamycin, cyclophosphamide and dacarbazine, with good response. The metastatic lesion was treated with $24 \mathrm{~Gy}$ of radiotherapy, while the primary tumor was treated with $50 \mathrm{~Gy}$ of radiotherapy. The patient underwent the Kraske approach with radical resection of the perirectal mass. The rectal wall was closed with interrupted silk sutures, and layered closure of incision over a drain was performed. An R0 resection was achieved. A laparoscopic diverting loop ileostomy to protect the rectal repair was performed.

Conclusion. The Kraske approach allows for adequate resection, while avoiding the morbidity of the transabdominal approach, and allowing the patient to maintain a continent rectum.

FUNDING Elliot A. Asare, Timothy J. Vreeland, and Barry W. Feig have no financial disclosures to declare.
Electronic supplementary material The online version of this article (https://doi.org/10.1245/s10434-018-6636-x) contains supplementary material, which is available to authorized users. (c) Society of Surgical Oncology 2018

First Received: 23 April 2018; Published Online: 6 July 2018

E. A. Asare, MD, MS

e-mail: eaasare@mdanderson.org 